\title{
BREVES CONSIDERAÇÕES SOBRE DECISÕES ELEITORAIS ILÍQUIDAS
}

\author{
MARCOS YOUJI MINAMI \\ Doutorando (UFBA), mestre (UFBA), especialista (UNISUL), \\ bacharel em Direito (UFC), professor de Processo Civil (FAP-CE), \\ professor convidado de Pós-Graduação em Processo Civil (URCA-CE) \\ e técnico judiciário (TRE-CE).
}

Em homenagem a José Carlos Barbosa Moreira, o maior processualista brasileiro de todos os tempos, que nos deixou em 26 de agosto de 2017.

Resumo: O presente artigo aduz que o juiz, mais do que estar proibido de declarar o non liquet, não pode deixar de realizar o comando decisório alegando não saber como fazê-lo ou não haver mecanismos, legais ou práticos, para isso. Também não pode proferir decisões sem explicitar como será seu cumprimento, levando em consideração os meios físicos disponíveis. A seguir, discute-se que uma das razões que podem causar a impossibilidade de execução é, justamente, uma decisão ilíquida. Uma das hipóteses levantadas é de que a maneira como fomos educados nas escolas jurídicas contribuiu para a forma como se decide, pensado apenas em dizer o direito, mas não como realizá-lo. Conclui-se pela necessidade de uma formação interdisciplinar para evitar decisões inviáveis bem como pela utilização, pelo magistrado, de medidas coercitivas para efetivar suas decisões. Partindo de um caso concreto, a pesquisa foi completamente bibliográfica. Palavras-chave: Processo Eleitoral; Processo Civil; Execução; Execução Indireta; Liquidação de Sentença.

\section{APRESENTAÇÃO}

Em 23 de setembro de 2010, em decisão liminar na Representação n. ${ }^{\circ}$ 6961-34.2010.6.06.0000, o Tribunal Regional Eleitoral do Ceará 
determinou, a pedido do Ministério Público Eleitoral, entre outras medidas, a busca e apreensão, em todo o Estado do Ceará, de todas as placas, cavaletes e assemelhados instalados em todas as praças públicas. A seguir, é possível conferir parte do dispositivo:

Assim, presentes os pressupostos de concessão da ordem de busca e apreensão, CONCEDO a ordem requerida pelo Ministério Público Eleitoral Auxiliar, determinando a expedição de ordem de busca e apreensão, a ser cumprido em todo o Estado do Ceará, pelas respectivas Comissões de Fiscalização de Propaganda, com o apoio da Polícia Federal, se necessário for, a fim de que sejam apreendidos todos os materiais de propaganda móvel que estejam sendo utilizados com as seguintes irregularidades:

a) placas, cavaletes e assemelhados instalados em praças públicas ou espaços públicos, como é o caso da Praça Portugal e Praça Manuel Dias Branco (Rotatória da Aguanambi), citadas apenas como exemplo;

b) placas, cavaletes e assemelhados instalados em canteiros de vias públicas, impedindo o regular tráfego de pedestres, de modo a obrigá-los a utilizar a via pública para alcançar local destinado à travessia da via pública;

c) placas, cavaletes e assemelhados instalados em calçadas e lugares equivalentes, impedindo ou dificultando o tráfego de pedestres, devendo ser assegurada a necessidade de espaço para a passagem de cadeiras de rodas e equipamentos de uso de pessoas com necessidades especiais e

d) placas, cavaletes e assemelhados mantidos ao longo das vias públicas ou em qualquer lugar que se lhes exija a mobilidade, após as vinte e duas horas, devendo para tanto ser destacada diligência específica para a observância do horário indicado.

Determino, ainda, que seja lavrado auto de apreensão circunstanciado, contando local, dia e hora da apreensão, assim como as circunstâncias que a autorizaram, para que se verifique se é necessária a interposição de representação específica com a finalidade de apenar o candidato. ${ }^{1}$

Sem entrar em detalhes acerca do mérito do provimento - seu acerto ou desacerto - o fato é que houve uma ordem a priori clara: a busca e apreensão de determinados materiais de campanha. Em termos mais técnicos, poder-se-ia afirmar estarmos diante de uma decisão certa e líquida, estabelecendo exatamente uma conduta a ser realizada. Observando com lente mais potente, porém, alguns detalhes não ficaram definidos. Quem

1 Decisão Liminar em 22/09/2010 - Representação N. ${ }^{\circ}$ 6961-34.2010.6.06.0000. Juiz Auxiliar. João Luís Nogueira Matias. 
deveria cumprir a ordem em municípios sem uma Comissão de Fiscalização de Propaganda instituída (e nem se entra aqui na discussão se estaria na atribuição dos servidores a realização desse tipo de diligência)? Quais veículos deveriam ser utilizados nesse cumprimento? Em qual local esses materiais deveriam ficar armazenados? Não havendo Polícia Federal, quem garantiria a segurança dos agentes estatais responsáveis pela medida executiva?

O presente estudo objetiva analisar por qual motivo é possível defender a iliquidez da decisão acima e em que medida esse tipo de defeito dificulta a realização dos comandos normativos na esfera eleitoral, bem como quais caminhos podem ser tomados para diminuir esse problema. Não se pretende a elaboração de um manual infalível de decisões realizáveis. A pretensão é antes a de provocar a doutrina para o início de um debate necessário sobre o tema.

\section{DESDOBRAMENTOS DA VEDAÇÃO AO NON LIQUET}

No período das ações do processo civil romano clássico, na fase apud iudicem, o iudex, não estando subordinado hierarquicamente a ninguém, poderia não julgar se não formasse convicção sobre a causa que apreciava. Como ensina Cruz e Tucci, ele "[...] poderia simplesmente declarar sibi non liquere (não me parece claro), ensejando que as partes retornassem ao magistrado para a escolha de novo julgador" (2013, p. 49). A expressão e a compreensão do que vem a ser non liquet remontam a essa época; e a necessidade política de sempre se solucionar o conflito foi restringindo tal possibilidade (CARNELUTTI, 2000, p. 428).

A principal causa de ocorrência do non liquet se dá quando o material probatório é insuficiente para formar a convicção do juiz acerca do direito pretendido. Para essa situação, o ordenamento jurídico costuma adotar alguns posicionamentos ${ }^{2}$. O primeiro é justamente autorizar a abstenção pelo magistrado, como ocorria no período romano clássico acima descrito ${ }^{3}$.

${ }^{2}$ Conforme descrito por Barbosa Moreira, com ampla referência, em: MOREIRA, José Carlos Barbosa. "Julgamento e ônus da prova". Temas de direito processual: (segunda série). São Paulo: Saraiva, 1988a, p. 74.

3 Atualmente, o non liquet não pode mais, em regra, ocorrer. Para o Brasil, há autores como Leonardo Greco que entendem haver algumas exceções: "São exceções a essa regra no Processo Civil: as ações coletivas, em que o juiz pode julgar o pedido improcedente por insuficiência de provas, não produzindo a sentença coisa julgada, nos termos do 
Outra possibilidade é a de autorizar ao órgão julgador a decidir conforme sua intima convicção "[...] ou, ainda, que dê ao litígio desate inspirado em considerações de eqüidade" (MOREIRA, 1988a, p. 74) ${ }^{4}$. Mas a solução mais utilizada, adotada inclusive em nosso sistema, é o instituto do ônus da prova. Permanecendo o órgão julgador na dúvida, mesmo após a fase instrutória, aquele que deveria provar o alegado e não logrou êxito na tarefa, impõe-se o prejuízo decorrente do descumprimento desse ônus: terá uma decisão contra si.

A decisão solicitada pelo jurisdicionado deve ser proferida em algum momento, mesmo que o magistrado ainda não esteja plenamente convencido ou não seja possível eliminar de maneira invencível sua dúvida ${ }^{5}$. Ela acontece ainda que traga tremenda insatisfação para uma das partes. Nesse contexto, cabe lembrar doutrina de Tércio Ferraz Jr. sobre o ato decisório. Ele não se confunde com o mero ato de escolha entre alternativas nítidas e claras, mas decorre de "[...] procedimento complexo em face de situação caracterizada pela insegurança. Podemos dizer, nesse sentido, que sua finalidade última é a absorção de insegurança" (FERRAZ JR., 2007, p. 326). Essa absorção não traduz a solução do conflito a contento para todos. Antes, significa que o problema terá um fim.

Ocorre que essa absorção de insegurança não trará o fim do problema se o provimento concedido não for efetivado quando for o caso. A decisão, no sentido de um ato jurisdicional vazado em texto, não é o que o jurisdicionado busca em grande parte das vezes que aciona a atividade estatal jurisdicional.

art. 18 da Lei n. 4.717/65, do art. 16 da Lei n. 7.347/85 e do art. 103 da Lei n. 8.078/90; e certas ações que versam sobre direitos indisponíveis em que, em desfavor desses direitos, sendo de elevado valor humano, o seu sacrifício somente deve ser admitido se os fatos contrários estiverem provados além de qualquer dúvida razoável, tal como no processo penal (beyond any reasonable doubt)" (GRECO, 2015). Os casos citados, contudo, não parecem configurar exceção. Neles, houve julgamento. O modo de trabalhar com a prova ou o regime de estabilidade da decisão é que são diferentes.

${ }^{4}$ No Brasil, a equidade é autorizada em alguns casos nos termos do parágrafo único do art. 140 do CPC Art. 140: "O juiz não se exime de decidir sob a alegação de lacuna ou obscuridade do ordenamento jurídico. Parágrafo único. O juiz só decidirá por equidade nos casos previstos em lei”. Aqui não há hipótese de ausência de material probatório, mas de possível lacuna ou obscuridade do ordenamento. Essas situações não abalam o que Pontes de Miranda chamou de "[....] dever formal de obrar" (MIRANDA, 1974, p. 338), imprescindível, segundo ele, para a solução de conflitos e realização dos direitos.

5 Parte-se aqui da premissa de que as questões processuais foram resolvidas e que cabe ao juiz apenas manifestar-se sobre o mérito. 
Nesse aspecto, mesmo havendo mecanismos para impedir o non liquet, se o comando do dispositivo não se concretizar, teremos, ainda assim, vedação de acesso à justiça. Ao juiz, é defeso deixar de julgar alegando não estar convencido da tese vencedora ou não saber qual o direito aplicável ao caso - o que, como visto, é chamado de vedação ao non liquet-, mas também, a ele não se permite deixar de realizar o comando decisório ou a prestação contida em título executivo extrajudicial ${ }^{6}$, afirmando não ser viável sua realização - o que aqui se batiza de vedação ao non factibile ${ }^{7}$. Proibir o non liquet, mas permitir o non factibile seria uma contradição?.

${ }^{6}$ O título executivo extrajudicial possui a mesma força executiva da decisão por imperativo legal. Isso será discutido no item que relacionará a execução ao título executivo.

7 A expressão não advém de nenhum brocardo latino consagrado, mas da tradução, em latim, de algo como "não é factível". Preferiu-se não utilizar essa expressão em português para se fazer um paralelo com "non liquet" e facilitar a veiculação da ideia. Nesse sentido, é possível utilizar-se a expressão "non est res factibilis" que, segundo o professor José Serrano, em consulta realizada, pode assim ser justificada: "non est res factibilis"; "não", traduz-se por "non", advérbio de negação; "é”, fica "est", terceira pessoa do singular do verbo "sum" (presente do indicativo). "Realizável”, fica "res factibilis". "Res" é nominativo singular do substantivo "res, ei”, quinta declinação latina e significa "coisa, matéria, assunto judiciário, questão judicial". "Factibilis" é adjetivo biforme dos adjetivos do segundo grupo e também é nominativo singular, pois está qualificando o substantivo "res". A expressão citada acima foi "non factibile", seguindo parecer solicitado a José Jerônimo de Morais, Professor Emérito, Titular de Filologia Românica e Latim (Departamento de Letras e Artes - Universidade Estadual de Feira de Santana/BA), justificando preferir " non factibile " fa cti bi l e - , por ser a forma do neutro (singular) e, semanticamente, denota certa abstração e generalização, equivalente a: isto, isso (o fato de não realizar a sentença) não é viável, exequível. Ademais, alertou José Jerônimo, em suas notas enviadas por correio eletrônico, que "[...] mais coerente com o sistema vigente de registro lexical do verbo seria o infinitivo => fàcere. Entre nós o 'Dicionário Latino Vernáculo' de Marques Leite e Novaes Jordão (etimologia - literatura - história - mitologia - geografia) ed. LUX ltda, Rio, 1956 (2 ed.), adotou esse critério [v.g.: fàcere (-io, -is; feci; factum)]. Os étimos gregos são transcritos no respectivo alfabeto; há referências ao sânscrito e outras fontes".

${ }^{8}$ Chiovenda explica que romanos não desprezaram a necessidade de se realizar o comando decisório e nisso justificou parcialmente o que chamava de autoridade da coisa julgada. Curiosamente, essa ideia está incrustrada, de alguma forma, em nosso Código, quando se estabelece, no art. 502 do CPC, o conceito de coisa julgada como "autoridade". Eis suas lições nesse sentido: "Para os romanos, como para nós, salvo as raras exceções em que uma norma expressa de lei dispõe diversamente [...], o bem julgado torna-se incontestável (finem controversiarum accipit): a parte a que se denegou o bem da vida não pode mais reclamar; a parte a quem se reconheceu, não só tem o direito de consegui-lo praticamente, em face de outra, mas não pode sofrer, por parte desta, ulteriores contestações a esse direito e esse gozo. Essa é a autoridade da coisa julgada. Os romanos a justificaram com razões inteiramente práticas, de utilidade social" (CHIOVENDA, 1998, p. 447).

${ }^{9}$ Barbosa Moreira ensina que segundo entendimento consagrado a atividade jurisdicional 
O problema da efetivação do comando constante no título executivo pode ter lugar no processo de execução ou no processo de conhecimento que eventualmente o antecede. No primeiro caso, isso pode ocorrer tanto na execução de títulos executivos extrajudiciais, como no cumprimento de sentença ${ }^{10}$. O segundo é observado apenas na execução de títulos executivos judiciais e acontece em, pelo menos, duas hipóteses: a impossibilidade de realizar decisões obscuras e a impossibilidade de realizar decisões materialmente impossíveis.

Decisão obscura é aquela incompreensível, nos termos tratados por Clóvis Kemmerich, em sua tese de doutorado. Se a decisão é obscura, é evidente que a sua realização é impossível. Segundo Kemmerich, é possível identificar níveis de gravidade dessa obscuridade. Há decisões (a) com obscuridade superável e decisões (b) com obscuridade insuperável (KEMMERICK, 2013, p. 54). Quanto à extensão, e sem excluir a possibilidade de situações intermediárias, há casos de “[...] (1) obscuridade restrita à fundamentação, (2) obscuridade restrita a uma parte da decisão de mérito e (3) obscuridade geral" (KEMMERICK, 2013, p. 54). A partir daí, propõe uma solução do problema a depender do grau de obscuridade e de qual parte da decisão o defeito é identificado.

As questões apontadas acima são pertinentes, mas não são resolvidas durante o procedimento executivo. A tese de Kemmerich é focada nos problemas relacionados à formação da decisão - são mais atinentes ao non liquet e não ao non factibile. Como dito, é evidente que decisão obscura não pode ser efetivada. Mas isso é problema a ser tratado no processo cognitivo ${ }^{11}$.

"[...] pode visar precipuamente a dois fins distintos: formular a norma jurídica concreta que deve disciplinar determinada situação, e atuar praticamente essa norma, dando-lhe palpável efetividade" (MOREIRA, 1988b, p. 177). Enquanto o non liquet está relacionado ao primeiro daqueles fins, o non factibile trata do segundo.

10 Tanto na chamada execução em processo autônomo como no cumprimento de sentença temos atividade executiva, mesmo que o cumprimento esteja previsto no livro de conhecimento. Aliás, esse fato recebeu críticas de Barbosa Moreira (MOREIRA, José Carlos Barbosa. 'CCumprimento' e 'execução' de sentença: necessidade de esclarecimentos conceituais". Temas de direito processual: (nona série). São Paulo: Saraiva, 2007, p. 317). As diferenças mais acentuadas desses dois "tipos" executivos dizem respeito às matérias possíveis de defesa para cada um deles.

11 Mesmo que para isso a parte prejudicada se valha de mecanismo batizado por Kemmerich de "demanda autônoma de interpretação" (KEMMERICK, 2013, p. 110). A leitura da obra de Kemmerich deixa claro que o assunto por ele pontuado diz respeito 
A atuação da atividade executiva começa - e somente é possível - quando o título está formado.

Outro problema na realização da decisão é o caso dos comandos irrealizáveis ou materialmente impossíveis. Sobre elas, Dinamarco chegou a defender que não seriam aptas à coisa julgada nos seguintes termos:

Mesmo as sentenças de mérito só ficam imunizadas pela autoridade do julgado quando forem dotadas de uma imperatividade possivel: não merecem tal imunidade (a) aquelas que em seu decisório enunciem resultados materialmente impossíveis ou (b) as que, por colidirem com valores de elevada relevância ética, humana, social ou política, também amparados constitucionalmente, sejam portadoras de uma impossibilidade jurídico-constitucional (DINAMARCO, 2005, p. 307).

Dois foram os problemas apontados: decisões materialmente impossíveis ou decisões com "impossibilidade jurídico-constitucional".

Sobre a "impossibilidade jurídico-constitucional", repete-se o que foi dito acima em relação às decisões obscuras. São questões a serem discutidas quando da construção da decisão no processo de conhecimento. O que não é possível é debater se uma tese é ou não constitucional e, por isso, irrealizável, no processo de execução. O título executivo, uma vez formado, é apto a autorizar a execução ${ }^{12}$. Eventual inconstitucionalidade do comando é problema com sede distinta de resolução.

Em relação às decisões materialmente impossíveis, Dinamarco exemplifica que seria inviável determinar que alguém caminhasse sobre um rio ou tirasse de uma cartola coelho que nunca lá entrou. Por fim, completa: “[...] sentenças assim trariam em si mesmas o germe de sua ineficácia, chegando

à cognição - formação do comando normativo do caso concreto - e não à execução. Poder-se-ia pensar que a obscuridade da decisão, no contexto da execução, poderia ser tratada na fase liquidatória. Também não é o caso. A liquidação serve para tornar decisão compreensível, mas incompleta, inteira. O objetivo é integrar a decisão.

${ }^{12}$ Isso não significa uma imunidade invencível da decisão. O sistema prevê uma série de mecanismos para discutir eventuais injustiças após a formação do título como a impugnação (art. 525 e $\iint$ ) e a ação rescisória (art. 966) naquilo que forem aplicáveis. Mas essas não são situações ideais de ocorrência no processo executivo e sua sede de estudo transcende esta pesquisa. 
ao ponto de serem juridicamente inexistentes porque jamais produziriam o efeito que nominalmente enunciassem" (DINAMARCO, 2005, p. 307) ${ }^{13}$. Embora não se concorde com a tese da inexistência da decisão inexequível, percebe-se aqui o reconhecimento da gravidade da ausência de entrega da tutela concedida. A decisão, porém, existe, pois proferida, em tese, em processo regular mediante provocação hábil e por agente competente para isso. O que se pode discutir é se seria válida ou, embora válida, ineficaz. Não é possível dizer que é válida, mas ineficaz, pois o plano da eficácia opera na seara normativa - ideal, portanto. Os efeitos impossíveis da decisão materialmente impossível não são jurídicos, mas práticos. O que há no caso é uma decisão defeituosa, inválida. Houve erro ao julgar no momento em que se escolheu uma opção de impossível realização ${ }^{14}$. A solução é uma nova decisão. Novamente, não se busca no procedimento executivo a resposta ao problema.

Visto as hipóteses de problemas na realização do título com origem no processo de conhecimento, passa-se aos casos em que eles ocorrem em sede executiva. Não sendo possível, a priori, indicar todas as situações possíveis de sua ocorrência, apontam-se aqui as mais conhecidas. O título executivo, judicial ou extrajudicial, a depender do caso, possui realização impossível/ dificultada nos casos de: complexidade do problema (basta pensar na implantação de uma complexa ação por parte da Administração Pública, como o fim de maus tratos em um presídio); ausência de patrimônio pelo executado; falta de esclarecimento, no comando decisório, da quantidade do bem da vida a ser entregue ou de como determinada prestação deve ser realizada; prestação originária que deixou de existir; prestação que somente

13 A lição é apresentada, inclusive, em conhecida obra literária. Nela, após se impressionar com o poder de um rei, o personagem conhecido como Pequeno Príncipe pediu a ele que ordenasse ao sol que se pusesse, ao que o rei respondeu: "se eu ordenasse meu general voar de uma flor a outra como borboleta, ou escrever uma tragédia, ou transformar-se numa gaivota, e o general não executasse a ordem recebida, quem, ele ou eu, estaria errado? [...] É preciso exigir de cada um o que cada um pode dar. [...] A autoridade se baseia na razão. Se ordenares a teu povo que ele se lance ao mar, todos se rebelarão. Eu tenho o direito de exigir obediência porque minhas ordens são razoáveis" (SAINT-EXUPÉRY, 2006, pp. 39-40).

14 Pode-se dizer tratar-se aqui de um defeito de atividade, um error in procedendo. Nas lições de Didier Jr. e Leonardo Cunha: “[...] os vícios de atividade, igualmente denominadores de errores in procedendo, ocorrem quando o juiz desrespeita norma de procedimento provocando prejuízo ao recorrente” (DIDIER JR.; CUNHA, 2017, p. 161). Um comando irrealizável constitui grande prejuízo. 
pode ser realizada por determinada pessoa que se nega peremptoriamente a fazê-lo ou simplesmente constata-se que é impossível, na forma estipulada, a entrega da tutela (tratamento de saúde a quem, por alguma debilidade decorrente da piora da doença, não pode mais dele dispor na forma concedida).

Sobre decisões complexas, remete-se ao estudo dos chamados processos estruturais ${ }^{15}$; sobre execução contra devedor sem patrimônio, a questão é resolvida pela insolvência civil $^{16}$; para coagir aquele que deve realizar uma prestação, utiliza-se a chamada execução indireta; para resolver os casos em que seguir o procedimento tipificado em lei não resolve, utilizam-se meios executivos atípicos ${ }^{17}$; para os casos em que a prestação

${ }^{15}$ Indicam-se, sobre o tema, os seguintes trabalhos, com ampla indicação bibliográfica: ARENHART, Sérgio Cruz. "Decisões estruturais no direito processual civil brasileiro". Revista de Processo, vol. 225/2013, p. 389, nov. 2013, discorrendo sobre as bases de compreensão do processo estrutural no Brasil; VIOLIN, Jordão. Protagonismo judiciário e processo coletivo estrutural. Salvador: Editora JusPodivm, 2013, discorrendo não apenas sobre a legitimação política para um protagonismo do judiciário, mas também sobre as diversas fases do processo coletivo estrutural como legitimação, instrução etc.; JOBIM, Marco Félix. Medidas estruturantes: da suprema corte estadunidense ao supremo tribunal federal. Porto Alegre, demonstrando como o problema se apresenta na Suprema Corte Americana e sua viabilidade de aplicação no STF: Livraria do Advogado Editora, 2013; LIMA, Edilson Vitorelli Diniz. $O$ devido processo legal coletivo: representação, participação e efetividade da tutela jurisdicional/ Tese de Doutorado. Curitiba: UFPR, 2016, além de discutir com profundidade sobre o que vem a ser o processo estrutural, pretende quebrar o paradigma da legitimação coletiva no Brasil; ARENHART, Sérgio Cruz. Processos estruturais/ Organizadores: Sergio Cruz Arenhart e Marco Félix Jobim. Salvador: Juspodivm, 2017. Esta última obra consiste em uma coletânea reunindo textos não apenas de especialistas brasileiros na área, como Vitorelli, Arenhart e Marco Felix, mas também contando com escritos de autores consagrados mundialmente como Mark Tushnet e Owen Fiss.

16 Veja art. 1.052 do CPC/2015 e Livro II, Título IV, do CPC/1973.

${ }^{17} \mathrm{O}$ princípio da atipicidade dos meios executivos decorre basicamente de três enunciados normativos do CPC: art. 139, IV, o art. 297 e o $₫ 1^{\circ}$ do art. 536 (DIDIER JR., CUNHA, BRAGA, OLIVEIRA, 2017). Sobre o tema: MINAMI, M.Y.. "Breves apontamentos sobre a generalização das medidas de efetivação no CPC/2015 - do processo para além da decisão". Novo CPC doutrina selecionada, v.5: execução/ Coordenador geral, Fredie Didier Jr.; organizadores, Lucas Buril de Macêdo, Ravi Peixoto, Alexandre Freire. - Salvador: Juspodivm, 2015, pp. 217-231. A não previsão de medidas expressas em lei não pode ser impedimento de entrega da tutela. Nas lições de Barbosa Moreira, "[...] o processo deve dispor de instrumentos de tutela adequados, na medida do possível, a todos os direitos [...] contemplados no ordenamento jurídico, quer resultem de expressa previsão normativa, quer se possam inferir do sistema" (MOREIRA, José Carlos Barbosa. "Notas sobre o problema da 'efetividade' no processo". Temas de direito processual: terceira série. São Paulo: 
originária, na hora da execução, não existe mais, a questão resolve-se, em muitos casos, pela entrega da tutela do equivalente. Por fim, sobre a falta de esclarecimento acerca da quantidade do bem da vida ou de como a prestação deve ser realizada, a resposta pode ser dada pelo procedimento de liquidação. É dele que trataremos a seguir ${ }^{18}$.

\section{DECISÕES LÍQUIDAS E ILÍQUIDAS}

A decisão, para ser realizada, precisa trazer em seu bojo os elementos necessários ao seu cumprimento. Dizemos isso, pois não é raro encontrarmos decisões conferindo direitos sem, contudo, trazer o caminho para que isso ocorra. No processo, ou isso deve ser resolvido de pronto na decisão ela deve explicitar como será realizada -, ou em etapa específica para o desiderato: a liquidação de sentença.

A decisão, por vezes, além de atribuir direito ao vencedor, precisa apontar algumas respostas ${ }^{19}:$ quem vai realizar aquilo concedido, como fará isso, em qual prazo etc. Se a decisão responde todas essas dúvidas, é chamada de decisão líquida. Ela deve ser a regra. Apenas excepcionalmente as decisões ilíquidas são aceitas ${ }^{20}$. É preciso que contingências da vida causem isso. Imagine uma decisão atribuindo ao responsável por um acidente a obrigação de arcar com o tratamento de saúde. Quanto tempo esse tratamento irá durar, quanto irá custar, quais especialidades serão necessárias, são questões possivelmente irrespondíveis quando do surgimento da sentença. Será preciso, em momento posterior, esclarecê-las.

Saraiva, 1984, p. 27).

${ }_{18}$ Pode assustar a quantidade de soluções possíveis no sistema para o problema apontado. Mas, como ensinou Barbosa Moreira, é ilusão pensar que apenas um remédio pode tratar dos diversos males que afetam a efetividade da atividade jurisdicional. "Temos de combinar estratégias e táticas, pondo de lado o receio de parecermos incoerentes se, para enfermidades de diferente diagnóstico, experimentarmos remédios também diferenciados" (MOREIRA, José Carlos Barbosa. "O futuro da justiça: alguns mitos". Temas de direito processual: oitava série. São Paulo: Saraiva, 2004, p. 7).

${ }^{19}$ Não se desprezam situações de decisões cuja efetivação prescinde de atos executivos como é o caso daquelas que reconhecem direitos potestativos e algumas declaratórias. Não é, contudo, objeto deste ensaio tratar do assunto.

${ }^{20}$ Para alguns, como Luiz Rodrigues Wambier, uma leitura mais atenta deixa claro que “[...] no CPC atual, essa diretriz é ainda mais incisiva e as hipóteses de liquidação ainda mais restritas". (2015). 
Delinear a decisão é tarefa por vezes árdua e as dificuldades ocorrem, inclusive, na própria delimitação do que pode ser feito na fase de liquidação de sentença. Isso, porque a influência da tradição romanista mostra-se presente aqui.

A liquidação de sentença, em sua compreensão tradicional, a partir da doutrina italiana, era vista como "[...] conjunto de atividades processuais destinadas a revelar o valor de uma obrigação, quando ainda não indicado no título executivo" (DINAMARCO, 2009, p. 713. ${ }^{21}$ Era preocupação da doutrina e da lei focar na delimitação do valor, mas não tratar de demais aspectos eventualmente omissos na decisão.

Com o tempo, passou-se a permitir a fase de liquidação de sentença não apenas para identificar o quantum, mas mensurar a prestação devida. Nesse sentido, Luiz Rodrigues Wambier defende casos de iliquidez na sentença “[...] também em qualquer situação em que não exista definição quanto à mensuração da quantidade de coisas, indicação de extensão, volume, medida e, portanto, à grandeza ou ao tamanho daquilo que deva ser prestado pelo devedor" (2015).

Todavia, o problema permanece nas prestações de fazer/não fazer. Como resolver as situações de decisões reconhecendo prestações sem indicar como realizá-las? O exemplo que pode ser dado desse tipo de situação é justamente o caso que inaugura este escrito.

Uma interpretação ampliativa do que pode ser feito na fase de liquidação de sentença resolve a dúvida do momento processual para o debate dessas questões, mas não explica como isso deve ser feito. Os artigos que tratam da liquidação da sentença são por demais sucintos - artigos 509 a 512 do CPC/15 - e não abarcam a complexidade dos casos possíveis. Aliás, a própria divisão do tema em: liquidação por arbitramento e liquidação pelo procedimento comum é enganosa. É que fica parecendo ser possível dividir em duas categorias a forma de solucionar o problema das sentenças ilíquidas.

${ }^{21}$ Mas é possível encontrar clássicos ensinando uma compreensão de liquidação mais ampla. Pasquale Castoro, por exemplo, há muito tempo escreveu: "In pratica si è proclivi a credere che la liquidità del diritto riguarda la sola espropriazione, mentre nella realtà concerne qualsiasi specie di esecuzione forzata" (CASTORO, 1964, p. 6). 
O fato é que muitas decisões padecem, em seu bojo, de maiores explicitações de como realizá-las. A doutrina nos ensina se temos o direito: Direito Civil, Constitucional, Administrativo, Eleitoral etc. Também nos diz como construir a decisão que confere esses direitos em caso de sua inobservância: Direito Processual. Aprendemos a diæer o direito e até nos preocupamos em efetivá-lo. Atrapalhamo-nos, contudo, na hora de ensinar nas academias como fazê-lo. O tópico seguinte propõe uma razão para isso.

\section{TRADIÇÃO JURÍDICA E EDUCAÇÃO JURÍDICA}

Um grande problema que surge ao magistrado na efetivação das decisões é o tipo de educação que ele recebeu nos bancos acadêmicos e mesmo em eventuais cursos de aperfeiçoamento. Atualmente, muitas são as informações necessárias para o desempenho da atividade judicante e variada é a gama de questões que batem à porta do judiciário ${ }^{22}$.

Não se pode dizer que esse fenômeno de acúmulo de conteúdo imprescindível à criação e aplicação do direito seja problema recente para os professores. E nem que se trata de algo exclusivo de nossa tradição romanista. Já em 1953, F. H. Lawson, jurista comparatista, referindo-se à realidade norte-americana, salientava o aumento da complexidade da vida em sociedade, com reflexos direto no Direito e seu ensino. Salas de aula cada vez mais numerosas, tempo exíguo para apresentação dos conteúdos sempre crescentes, acarretando um ensino de massa com discussões cada vez mais rasas e professores despreparados (LAWSON, F. H.,1953, p. viii).

Muito da educação jurídica da América Latina teve os códigos como ponto central ${ }^{23}$. Uma das razões para isso era a necessidade de se estudar

22 O acesso à justiça no Brasil é amplo. Um dos fatores que agrava a situação é a ausência de atitude pelas outras funções estatais (Legislativo e Executivo) em alguns problemas sociais, ou pela sua ineficiência, ou para evitar tratar de questões que tragam desacordos morais razoáveis. Os desacordos morais razoáveis são questões cujo consenso é praticamente inalcançável. "Pessoas bem-intencionadas e esclarecidas, em relação a múltiplas matérias, pensam de maneira radicalmente contrária, sem conciliação possível”. (BARROSO, 2011, p. 248.) Por conta disso, a normatização e o trato dessas questões se tornam ou dificultosos ou são evitados pelas esferas legislativa e executiva. Sobra ao jurisdicionado recorrer ao judiciário. Isso é dito aqui pois essas questões normalmente requerem dos agentes jurisdicionais do Direito um repertório teórico interdisciplinar, que não possuem.

23 PERDOMO, Rogelio Pérez. "Reformar la educacion juridica ¿Tarea para sísifo?” Revista de Pedagogía Universitaria y Didáctica del Derecho. Vol 3. \# 1. Santiago. Chile. 2016, versão eletrônica. 
um direito eminentemente nacional, desvencilhado daquele aplicado nas nações que ora haviam subjugado as colônias. A codificação desempenhava um papel não apenas de unificação nacional, mas de superação de alguns paradigmas do passado ${ }^{24}$.

Como afirma Pérez Perdomo, essa visão de ensino de direito também foi responsável pelo surgimento de uma literatura apropriada para ela: o manual de direito, livro que expressa o monólogo do professor ao aluno, pensado com fins de facilitar o ensino dos códigos (PÉREZ PERDOMO, 2016).

Mas é importante, nesse momento, salientar como ocorria a educação jurídica nos países de tradição common law. Na Inglaterra, embora por muito tempo universidades ensinassem o Corpus Juris Civilis, a Revolução Gloriosa fez desaparecer os advogados formados nessa perspectiva e, por muito tempo, no território inglês, perdeu-se o sentido prático de se estudar Direito nas universidades (PÉREZ PERDOMO, 2016).

Já nos Estados Unidos, a maneira de educar advogados manteve-se muito informal. Quem estivesse interessado no Direito teria uma educação generalista, lendo quase que de forma autônoma obras jurídicas. Os estudantes faziam por vezes um estágio com um advogado experiente e, quando estivessem mais preparados, um juiz os reconhecia como advogados. Alguns eram autodidatas, como foi o caso de Abraham Lincoln (PÉREZ PERDOMO, 2016). Esforços foram envidados para a criação de centros de ensino jurídico. A mais exitosa dessas experiências ocorrera em Harvard.

Um dos fatos mais curiosos nesse contexto apontado por Pérez Perdomo a partir dos estudos de um jurista comparatista, Damaska, era que enquanto um estudante no Estados Unidos aprendia importantes destrezas sem uma prévia visão mais sistemática do Direito, um estudante na Itália enchia-se de conteúdo sem aprender destreza nenhuma (PÉREZ PERDOMO, 2016) ${ }^{25}$. Essa forma de estudar o Direito no Brasil é observada até hoje e precisa ser repensada.

${ }^{24}$ Características típicas observáveis nos povos de tradição civil law quando codificavam (MERRYMAN, PÉREZ PERDOMO, 2009, p. 55).

25 É por isso que já se chegou a afirmar que: “Os juízes da common law são solucionadores de problemas, muito mais do que teóricos, e a ênfase da civil law no cientificismo, na sistematização, no formalismo e em coisas do gênero acaba por obstruir a solução de problemas" (MERRYMAN, PÉREZ PERDOMO, 2009, p. 103). 
Não se defende aqui uma reforma completa na forma de se ensinar o direito. Mas é preciso repensar a fórmula atualmente adotada. É curioso o fato de livros que tratam de efetivação de decisões passarem longe de casos concretos. E talvez a jurisprudência também não forneça guia para a solução dos problemas. O precedente é paradigma de solução surgido em um caso e aplicável em outro semelhante futuro. Mas ele apenas costuma dizer se há ou não determinado direito, surgindo, portanto, na formação da decisão. Os problemas na execução surgem após a decisão.

Mas outro obstáculo na solução dos problemas pelo magistrado é o isolamento do direito de outras áreas do conhecimento. Não há, em regra, diálogo entre as ciências e isso impede tomada de decisões mais afinadas à realidade. Loïc Cadiet já chegou mesmo a afirmar a necessidade de uma abertura do processo civil a considerações de outras searas como a economia, sociologia e filosofia da justiça (CADIET, 2010, p. 5). No mesmo sentido advertiram Manuel Atienza e Rodolfo Luís Vigo, quando da apresentação do Código Ibero-Americano de Ética Judicial, que nossa cultura jurídica dominante foi concebida "com muita frequência, de maneira 'insular', de modo que havia uma tendência de se operar nele mesmo, sem levar em conta as dimensões que se consideravam simplesmente alheias ao mundo do Direito, como as da política, da ética ou da economia" (ATIENZA, 2008, p. 24).

Adotar soluções oriundas de outras ciências pode trazer novos caminhos à doutrina jurídica, com inusitadas soluções para velhos problemas. A seguir, um pequeno exemplo disso será apresentado.

\section{NOVOS CAMINHOS NA EFETIVAÇÃO DAS DECISÕES - PROVOCAÇÕES}

Não é de hoje a divulgação de estudos sobre a aplicação de outras ciências ao direito. A análise econômica do direito, bastante difundida por Richard Posner é bem conhecida por muitos doutrinadores. Causa curiosidade, contudo, perceber como são poucos os reflexos práticos dessas teorias não apenas da análise econômica do Direito, mas outros estudos tão sérios quanto - na execução civil, justamente a parte do processo responsável, na maioria dos casos, pela entrega ao jurisdicionado de seu pleito. Talvez se pense na impossibilidade de aplicá-las na prática. É preciso analisar se é esse mesmo o caso. 
Um importante livro sobre execução é de autoria de Larry Bossidy e Ram Charam: "execução - a disciplina para atingir resultados" (2005). Talvez, muitos juristas nunca tenham ouvido falar nesses nomes. A razão é simples. Os autores citados não são da área legal. Trata-se de obra destinada a grandes executivos procurando demonstrar que a atividade executiva possui tanta ou talvez mais importância do que a de planejar. Não adianta estabelecer objetivos, se não se consegue executá-los. Em "juridiquês": não basta uma decisão inexequivel.

$\mathrm{Na}$ obra, explica-se que de nada adianta elaborar estratégias impressionantes se não se consegue executá-las. Para isso, sete comportamentos essenciais são salientados (BOSSIDY, CHARAM; 2005; pp. xxiii a xxxii): Conhecer seu pessoal e sua empresa; insistir no realismo; estabelecer metas e prioridades claras; concluir o que foi planejado; recompensar quem faz; ampliar as habilidades das pessoas e conhecer a si próprio. $\mathrm{Na}$ efetivação das decisões, esses comportamentos podem trazer alguma diferença.

O magistrado precisa conhecer bem o que faz e os limites da atuação do judiciário, considerando os recursos que este possui. Precisa saber com quem pode contar, dentro e fora de sua secretaria ou Zona Eleitoral, não impedindo a manifestação dessas pessoas. É preciso saber lidar com as incertezas e com os recursos existentes. Não adiantam decisões fantásticas, mas inexequíveis. É preciso saber lidar com as prioridades - de se pensar, nesse contexto, como são estabelecidas as metas cobradas pelo CNJ. É preciso saber como concluir (finalizar) o que foi decidido, mesmo que em etapas. Recompensar a equipe é algo essencial. Os serventuários da justiça precisam sentir-se valorizados e não compelidos a agir de maneira instintiva ou improvisada ${ }^{26}$. Ampliação de capacidades existentes e, por fim, o juiz precisa se conhecer, sabendo seus limites e abrir-se ao diálogo. Pessoas de outras áreas podem eliminar pontos cegos e deficiências. O instituto do amicus curiae é interessante nesse sentido ${ }^{27}$.

\footnotetext{
${ }^{26}$ E nem se discute aqui ordens não razoáveis ou ilegais, mas que, mesmo assim, são cumpridas. $\mathrm{O}$ assédio moral no judiciário é um problema existente, mas pouco discutido.

${ }^{27}$ Embora o TSE tenha disposto, na sua Resolução n. ${ }^{\circ} 23.478$, de 10 de maio de 2016, em seu art. $5^{\circ}$, que "Não se aplica aos feitos eleitorais o instituto do Amicus Curiae de que trata o art. 138 da Lei n. ${ }^{\circ}$ 13.105, de 2015".
} 
Alguns juízes reclamam que não fizeram concurso para gerir secretarias e que a atividade administrativa toma muito de seu tempo. O fato de muitas das decisões não se preocuparem na forma de sua efetivação representa bem essa realidade. Conquanto isso seja verdade, não se pode dizer que assumiram essa função sem saber disso, pois a situação estrutural do judiciário é de conhecimento geral. Se o empecilho é incontornável, pelo menos em curto prazo, é preciso saber lidar com ele e talvez literatura não jurídica ajude muito nesse sentido.

A menção a um livro de gestão em artigo que trata de liquidação e efetivação de decisão foi apenas uma provocação. $\mathrm{Na}$ verdade, muito do que se pretendia pontuar já foi realizado e é chegado o momento de concluirmos. Antes, porém, é preciso apontar uma solução para o problema que inaugurou este artigo, de aplicação mais imediata e a partir de doutrina tradicional jurídica. É que as mudanças propostas acima requerem tempo para discussão, maturação e aplicação. Mas os problemas na seara eleitoral são prementes e constantes. Para tentar ajudar nesse debate, remetemos ao próximo tópico.

\section{EXECUÇÃO DIRETA E EXECUÇÃO INDIRETA}

Já se classificou, no Brasil, a execução direta ou indireta a partir do objeto da execução. Foi assim nas lições de Affonso Fraga: "quanto ao seu objecto a execução é directa ou indirecta; aquella tem logar quando recahe directamente sobre a coisa que constituiu objecto da acção ou do título provido de força executiva, esta quanto versa sobre prestação diversa da ajuizada" (FRAGA, 1922, p. 69).

$\mathrm{Na}$ época da vigência das Ordenações Filipinas no Brasil, eram três as formas de execução admitidas. Em matéria civil ou comercial, havia a execução direta e "pignoris capio" e em matéria comercial, quando da pluralidade de credores, tínhamos a "distractio bonorum" (FRAGA, 1922, p. 41). Nesse tempo, nas prestações de "faciendo", não se podendo obrigar o inadimplente a fazer o que se obrigara, a execução recaia sobre perdas e danos, surgindo um exemplo de coerção indireta (FRAGA, 1922, p. 60).

Os sentidos empregados acima não são os que guiarão este artigo, pois, atualmente, o que Affonso Fraga tratava de execução direta, é conhecida 
como execução para entrega da tutela específica - o que deve ser a regra -, enquanto a execução indireta daquela época corresponde à atual execução pela tutela do equivalente.

Doutrina moderna costuma diferenciar as execuções direta e indireta do seguinte modo: "a execução direta se dá através de meios executivos que permitem a realização do direito independentemente da vontade do réu, ao passo que a execução indireta objetiva a realização do direito mediante meios de execução que atuam sobre a sua vontade, objetivando convencê-lo a adimplir" (MARINONI, ARENHART, MITIDIERO; 2015). A primeira atuaria pelos chamados meios de substituição ou sub-rogação, enquanto a segunda, pelos meios de coerção.

É preciso analisar com mais cuidado essa distinção.

Costuma-se trazer como exemplo de execução direta aquela que ocorre mediante penhora seguida por alienação judicial. A qualificação destes atos na categoria da execução direta estaria justificada na medida em que ocorreriam independentemente da vontade do executado. $\mathrm{O}$ exemplo clássico de execução indireta seria aquela na qual haveria a imposição de multa - astreintes - no caso de inexecução da prestação determinada. O requerido, para não sofrer o prejuízo, realizaria a prestação por conta própria.

Bem pensadas as coisas, a qualificação de um ato como atinente à execução direta ou indireta a partir do parâmetro da vontade do requerido encontra uma inconsistência. É que pode ocorrer de o Estado realizar os chamados atos de sub-rogação - execução direta - em consonância com a vontade do requerido. Basta pensar no exemplo de executado de prestação de quantia que indica patrimônio para ser penhorado e até está de acordo com sua venda.

$\mathrm{Na}$ verdade, se é para pensar em um parâmetro para caracterizar a execução direta, este seria o fato de sua realização ocorrer pelo Estado-juiz ou por terceiro em alguns casos. Os atos de penhora e alienação, no exemplo acima, podem até ocorrer sem muita resistência pelo executado - e, às vezes, até com sua concordância -, mas eles não são realizados, em regra, por ele.

Por outro lado, a lição tradicional de que a execução indireta ocorre com a concordância do executado é parcialmente correta. Se é certo que 
a ação executiva é realizada por ele, não é possível afirmar que seja sua vontade fazê-lo. Ele foi compelido para isso. Mas o contrário também é possível, ou seja, mesmo sendo intimado a realizar algo sob pena de sofrer algum prejuízo (ou mesmo na expectativa de receber algum benefício como é o caso da sanção premial), é possível que, no momento de agir, o requerido o faça realmente convencido de estar realizando a conduta correta. Nessas duas situações, o que podemos identificar para caracterizar a execução indireta, é o fato de que a realização do ato executivo ocorre diretamente pelo requerido e não pelo Estado juiz.

A partir do que caracteriza cada uma das situações acima, a classificação entre execução direta/indireta adotada terá como base justamente o seguinte elemento: "quem realiza o ato executivo".

$\mathrm{Na}$ execução direta os atos executivos são realizados por agentes estatais - ou por alguém indicado pelo Estado -, enquanto na execução indireta tais atos são realizados diretamente pelo requerido. Em ambos os casos, a vontade do requerido é irrelevante. Não interessa, em nenhuma dessas situações, se o requerido, no fundo, está ou não de acordo com a conduta a ser realizada (penhora, entrega de coisa, realização de serviço etc.).

A utilidade prática dessa distinção é que, na execução direta, como os atos executivos são realizados pelo Estado (ou terceiro), em regra, há mais custos envolvidos. Mesmo se em um segundo momento houver ressarcimento desses valores, a existência deles pode, a priori, atrasar a realização desses atos. Nesse contexto, não se pode olvidar das situações, como na Justiça Eleitoral, em que não há custas envolvidas e, por isso, a própria Justiça Especializada precisa arcar, mediante utilização de seus recursos materiais e humanos, com a realização do ato, muitas vezes sem condições para fazê-lo.

$\mathrm{Na}$ execução indireta, por outro lado, os atos executivos são realizados pelo próprio responsável e isso pode ser algo mais vantajoso para o Estadojuiz, pois não deverá arcar, em tese, com nada para sua ocorrência.

O atual Código de Processo Civil - doravante CPC - abriu ampla possibilidade para a utilização das medidas coercitivas - execução indireta. No CPC de 1973, havia a previsão do $\int 5^{\circ}$, do art. 461, que possibilitava ao 
juiz, para a efetivação da tutela ou obtenção do resultado prático equivalente, "[...] de ofício ou a requerimento, determinar as medidas necessárias, tais como a busca e apreensão, remoção de pessoas e coisas, desfazimento de obras, impedimento de atividade nociva, além de requisição de força policial". O CPC/2015 não só trouxe medida semelhante em seu art. 536 e parágrafos, como generalizou a possibilidade de medidas executivas atípicas (entre elas as medidas coercitivas). Isso porque, no art. 139 da Parte Geral do CPC/2015, ao tratar dos poderes do juiz, permitiu-se a ele "[...] determinar todas as medidas indutivas, coercitivas, mandamentais ou sub-rogatórias necessárias para assegurar o cumprimento de ordem judicial, inclusive nas ações que tenham por objeto prestação pecuniária”.

A aplicabilidade do art. 139, IV, do CPC/2015, ao processo eleitoral é possível não apenas por tratar dos poderes do juiz como um todo, mas também pela possibilidade de aplicação do CPC/2015 à seara eleitoral nos termos de seu art. 15: "na ausência de normas que regulem processos eleitorais, trabalhistas ou administrativos, as disposições deste Código lhes serão aplicadas supletiva e subsidiariamente". Ademais, o Tribunal Superior Eleitoral, ao estabelecer diretrizes gerais para a aplicação do CPC/2015 no âmbito da Justiça Eleitoral, através da Resolução n. ${ }^{\circ}$ 23.478, de 10 de maio de 2016, não trouxe qualquer óbice para isso. Nesse sentido, não há impedimento para utilização, na esfera eleitoral, de quaisquer artigos que tratem dos poderes do juiz para efetivar suas decisões, provisórias ou definitivas, como os artigos 139, IV, 297 e 536.

\section{CONCLUSÕES}

As decisões no processo eleitoral, notadamente pertinentes à propaganda eleitoral, não raro trazem em seu bojo o problema da iliquidez no sentido aqui descrito. Voltemos ao provimento que inaugura este artigo. Ali se determinou a busca e apreensão de uma enorme quantidade de materiais e em inúmeros locais. Para as Zonas Eleitorais da capital, onde se costuma formar uma Comissão de Fiscalização de Propaganda Eleitoral, aparelhada com servidores e veículos, o cumprimento torna-se facilitado. Para as Zonas Eleitorais do interior, a realidade é completamente diferente. Nelas, é comum não haver servidores suficientes nem veículos à disposição para fiscalização. O apoio de segurança também é ponto sensível. 
É importante ressaltar que, durante a campanha eleitoral, decisão como a citada acima é apenas um exemplo das inúmeras que ocorrem. Nesse período, as seguintes ordens são bastante frequentes: determino a busca e apreensão de materiais como camisetas, adesivos, impressos; determino a retirada de propaganda irregular em determinado bem particular ou público; determino a retirada de propaganda eleitoral em determinado veículo; determino a busca e apreensão de veículos como carro de som, trio elétrico ou "paredão de som"; determino o fechamento de comitê ou que se diligencie para que se cumpra o limite de som permitido; determino a fiscalização ou impedimento de carreatas, passeatas ou comícios etc.

Nos casos acima, não havendo explicitação de como realizar a conduta determinada, o que se costuma fazer é improvisar. Improvisa-se, por exemplo, quando um servidor realiza atos de busca e apreensão em seus veículos particulares e sem qualquer apoio de segurança. Há improviso quando o servidor, sem qualquer material de segurança escala em árvores ou postes para retirar propaganda indevida ou vai pessoalmente e sozinho fiscalizar a realização de uma carreta ou comício.

Mas o improviso traz riscos aos servidores e precisa ser evitado.

Este artigo apontou duas possíveis soluções para os problemas levantados.

A primeira é uma educação interdisciplinar aos operadores do Direito para tentar buscar soluções não tradicionais, mas igualmente eficientes. É preciso parar de se ensinar o direito a partir de enunciados normativos e focar no estudo de casos, abrindo o diálogo com outras searas do conhecimento. $\mathrm{O}$ magistrado não profere decisões ilíquidas por não saber a técnica, mas, muitas vezes, por não ter aprendido nos bancos acadêmicos como resolver problemas práticos. Os Tribunais precisam pensar se não é o caso de se criarem setores com equipes multidisciplinares para dar suporte/ treinamento aos magistrados para quando se depararem com situações de difícil solução prática. E isso não é tão inusitado assim. Causas que envolvem crianças e adolescentes, por exemplo, costumam contar com apoio de equipes multidisciplinares.

A segunda solução para os problemas apontados neste estudo é a possibilidade de utilização, pelo magistrado, da execução indireta. Vimos que há lastro normativo para isso. Basta agora a aplicação prática. 
É preciso pensar, por exemplo, em formas que façam com que os próprios candidatos ou coligações/partidos diligenciem no sentido de desfazer ou evitar o ilícito eleitoral. Determinar a não realização de um ato sob pena de multa é medida por vezes utilizada, mas não raro mostrase ineficiente, pois o candidato/coligação/partido, ou sabe que não terá patrimônio para pagar a multa quando da futura execução, ou simplesmente não se importa com isso, pois o que se quer é ganhar a eleição a qualquer custo. É necessário refletir acerca de medidas coercitivas mais eficazes.

Nesse sentido, propõe-se analisar se seria possível, por exemplo, determinar a retirada ou cessação, pelo candidato, de uma propaganda ilícita, sob pena de não poder esse candidato participar da propaganda eleitoral gratuita (ou, quiçá, nenhuma outra propaganda como atos públicos) enquanto a ordem não for cumprida. Ou se não seria possível estabelecer como medida coercitiva a ameaça de que determinada propaganda, enquanto permanecer ilícita e não for alterada ou removida, será considerada na prestação de contas na rubrica de gasto irregular, o que pode contribuir para desaprovação nas contas, e isso pode ter efeito terrível para os eleitos. $\mathrm{Na}$ corrida eleitoral, propaganda eleitoral e possíveis problemas na futura eventual diplomação são duas moedas bem fortes.

Por fim, é preciso repensar ordens não apenas ilíquidas, mas ilegais, como aquelas que determinam aos servidores que realizem atos de investigação de compra de votos ou demais crimes eleitorais, fiscalização em locais perigosos ou fora do horário de expediente ou quaisquer ações que transcendam as atribuições dos servidores. É importante salientar que muitos se acham coagidos moralmente a não realizar o que foi determinado. Por outro lado, nunca se fez um estudo sério acerca dos limites da atuação dos servidores da Justiça Eleitoral. O serviço sempre é realizado e as ordem quase sempre cumpridas, mas é preciso analisar a que custo e quem irá responder no caso de algum dano sofrido por esses agentes estatais. Mas todas essas últimas questões pontuadas são assunto para um outro estudo.

\section{REFERÊNCIAS}

ARENHART, Sérgio Cruz. "Decisões estruturais no direito processual civil brasileiro”. Revista de Processo, vol. 225/2013, p. 389, nov. 2013. 
ATIENZA, Manuel. Código ibero-americano de ética judicial / Manuel Atienza e Rodolfo Luís Vigo. - Brasília: CJF, 2008.

BARROSO, Luís Roberto. “Constituição, democracia e supremacia judicial: direito e política no Brasil contemporâneo". As novas faces do ativismo judicial/ Organizadores André Luiz Fernandes Fellet, Daniel Giotti de Paula e Marcelo Novelino. Salvador: Editora JusPodivm, 2011.

BOSSIDY, Larry. Execução: a disciplina para atingir resultados/ Larry Bossidy, Ram Charam, com Charles Burck; tradução de Elaine Pepe. Rio de Janeiro: Elsevier, 2005.

BRASIL. Tribunal Regional Eleitoral. Decisão Liminar em Representação Eleitoral n. ${ }^{\circ}$ 6961-34.2010.6.06.0000. Julgamento em 22-09-2010. Juiz Auxiliar João Luís Nogueira Matias.

CADIET, Loïc. Théorie générale du procès / Loïc Cadiet, Jacques Normand, Soraya Amrani Mekki. Paris: Presses Universitaires de France, 2010.

CARNELUTTI, Francesco. Sistema de direitoprocessual civil/ V. 4. Procedimento do Conhecimento. Traduzido por Hiltomar Martins Oliveira. 1. ed. São Paulo: Classic Book, 2000.

CASTORO, Pasquale. Il processo di esecuqione nel suo aspetto pratico. Milão: Giufrè, 1964.

CHIOVENDA, Giuseppe. Instituições de direito processual civil/ Tradução: Paolo Capitanio. Vol. I. Campinas: Bookseller, 1998.

DIDIER JR. Fredie. Curso de direito processual civil: execução/ Fredie Didier Jr., Leonardo Carneiro da Cunha, Paula Sarno Braga, Rafael Alexandria de Oliveira. 7. ed. , rev., ampl. e atual. Salvador, JusPodivm, 2017.

DIDIER JR., Fredie; CUNHA, Leonardo Carneiro da. Curso de direito processual civil: o processo civil nos tribunais, recursos, ações de competência originária de tribunal e querela nullitatis, incidentes de competência originária de tribunal. 14. ed. reform. Salvador: Ed. JusPodivm, 2017.

DINAMARCO, Cândido Rangel. Instituições de direito processual civil: volume III. 5. ed. São Paulo: Malheiros, 2005. . Instituições de direito processual civil: volume IV. 3. ed. rev. e atual. São Paulo: Malheiros Editores, 2009. 
FERRAZ JUNIOR, Tércio Sampaio. Introdução ao estudo do direito: técnica, decisão, dominação. 5. ed. São Paulo: Atlas, 2007.

FRAGA, Affonso. Theoria e pratica na execução das sentenças. São Paulo: C. Teixeira \& C. Editores, 1922.

GRECO, Leonardo. Instituições de processo civil, volume II. 3. ed. Rio de Janeiro: Forense, 2015. Edição eletrônica.

JOBIM, Marco Félix. Medidas estruturantes: da suprema corte estadunidense ao supremo tribunal federal. Porto Alegre: Livraria do Advogado Editora, 2013.

KEMMERICK, Clovis Juarez. Sentença obscura e trânsito em julgado. Porto Alegre: Livraria do Advogado Editora, 2013.

LAWSON, F. H. A common lawyer looks at the civil law. University of Michigan: Ann Arbor, 1953.

LIMA, Edilson Vitorelli Diniz. O devido processo legal coletivo: representação, participação e efetividade da tutela jurisdicional/ Tese de Doutorado. Curitiba: UFPR, 2016.

MARINONI, Luiz Guilerme; ARENHART, Sérgio Cruz; MITIDIERO, Daniel. Novo curso de processo civil: tutela dos direitos mediante procedimento comum, volume II/ Livro Eletrônico. São Paulo: Editora Revista dos Tribunais, 2015. MERRYMAN, John Henry, PÉREZ-PERDOMO, Rogelio. A tradição da civil law - uma introdução aos sistemas jurídicos da Europa e da América Latina / Cássio Casagrande (trad.). Porto Alegre: Sérgio Antonio Fabris Editor, 2009.

MINAMI, M.Y.. "Breves apontamentos sobre a generalização das medidas de efetivação no CPC/2015 - do processo para além da decisão”. Novo CPC doutrina selecionada, v.5: execução/ Coordenador geral, Fredie Didier Jr.; organizadores, Lucas Buril de Macêdo, Ravi Peixoto, Alexandre Freire. Salvador: Juspodivm, 2015, pp. 217-231.

MIRANDA, Francisco Cavalcanti Pontes de. Comentários ao código de processo civil- Tomo II. Rio de Janeiro: Forense, 1974.

MOREIRA, José Carlos Barbosa. ''Cumprimento' e 'execução' de sentença: necessidade de esclarecimentos conceituais". Temas de direito processual: (nona série). São Paulo: Saraiva, 2007.

- "Julgamento e ônus da prova". Temas de direito processual: (segunda série). São Paulo: Saraiva, 1988a. 
. "Liquidação de Sentença. Correção monetária não pedida nem determinada pela sentença liquidanda. Recurso cabível e procedente". Temas de direito processual: (segunda série). São Paulo: Saraiva, 1988b.

. "Notas sobre o problema da 'efetividade' no processo" Temas de direito processual: terceira série. São Paulo: Saraiva, 1984.

. "O futuro da justiça: alguns mitos". Temas de direito processual: oitava série. São Paulo: Saraiva, 2004.

PERDOMO, Rogelio Pérez. "Reformar la educacion juridica ¿'Tarea para Sísifo?" Revista de Pedagogía Universitaria y Didáctica del Derecho. Vol 3. \# 1. Santiago. Chile. 2016, versão eletrônica.

SAINT-EXUPÉRY, Antoine de. O pequeno príncipel Tradução de Dom Marcos Barbosa. Rio de Janeiro: Agir, 2006.

TUCCI, José Rogério Cruz e. Lições de história do processo civil romano/ José Rogério Cruz e Tucci, Luís Carlos de Azevedo. 2. ed. São Paulo: Editora Revista dos Tribunais, 2013.

VIOLIN, Jordão. Protagonismo judiciário e processo coletivo estrutural. Salvador: Editora JusPodivm, 2013.

WAMBIER, Luiz Rodrigues Wambier. Breves comentários ao Novo Código de Processo Civil/ Tereza Arruda Alvim Wambier... [et al.], coordenadores. São Paulo: Editora Revista dos Tribunais, 2015, livro eletrônico. 